\title{
Differences in Gait Patterns of Unilateral Transtibial Amputees With Two Types of Energy Storing Prosthetic Feet
}

\author{
Ja Ryung Yang, $\mathrm{MD}^{1}$, Hee Seung Yang, $\mathrm{MD}^{1}$, Da Hyun Ahn, $\mathrm{MD}^{1}$, \\ Dong Young Ahn, $\mathrm{CPO}^{2}$, Woo Sob Sim, $\mathrm{CPO}^{2}$, Hea-Eun Yang, $\mathrm{MD}^{1}$ \\ ${ }^{1}$ Department of Rehabilitation Medicine, \\ ${ }^{2}$ Center of Prosthetics and Orthotics, Veterans Health Service Medical Center, Seoul, Korea
}

Objective To evaluate if there is a difference in gait pattern when applying two different shapes of energy storing prosthetic feet for trainstibial amputation we conducted a comparative study. Energy storing prosthetic feet for transtibial amputation are increasing in use, but there are few studies that evaluate the effects of the shape of energy storing feet on gait patterns.

Methods Ten unilateral transtibial amputees were recruited. Two different shapes of dynamic response feet were applied to each subject either 1C30 Trias or 1C60 Triton. The main differences between the two are a split forefoot and the presence of a heel wedge. Spatiotemporal, kinematic, and kinetic data was obtained through gait analysis. Differences between intact and prosthetic side and differences between the two prosthetics were assessed.

Results On a side to side comparison, cadence asymmetry with 1C30 Trias was observed. Ankle plantarflexion at the end of stance and ankle supination at the onset of preswing was smaller with both prosthetic feet compared to the intact side. Other spatiotemporal, kinematic, and kinetic data showed no significant differences in a side to side comparison. In a comparison between the two prosthetics, stance and swing ratio and ankle dorsiflexion through mid-stance was closer to normal with 1C60 Triton than 1C30 Trias. Other spatiotemporal, kinematic, and kinetic data showed no statistically significant differences between prosthetics.

Conclusion Both energy storing feet implants showed symmetric gait in unilateral transtibial amputees who are functionally independent in daily living. And 1C60 Triton showed closer to normal gait patterns than 1C30 Trias in our study.

Keywords Amputation, Prosthesis, Gait

Received August 18, 2017; Accepted October 18, 2017

Corresponding author: Hea-Eun Yang

Department of Physical Medicine and Rehabilitation, Veterans Health Service Medical Center, 53 Jinhwangdo-ro 61-gil, Gangdong-gu, Seoul 05368, Korea. Tel: +82-2-2225-1303, Fax: +82-2-2225-1579, E-mail: yangmary429@gmail.com

ORCID: Ja Ryung Yang (http://orcid.org/0000-0003-0581-5041); Hee Seung Yang (http://orcid.org/0000-0003-2492-7065); Da Hyun Ahn (http://orcid. org/0000-0003-0455-0731); Dong Young Ahn (http://orcid.org/0000-0002-3925-9525); Woo Sob Sim (http://orcid.org/0000-0002-0760-3918); Hea-Eun Yang (http://orcid.org/0000-0002-4449-7288).

(c) This is an open-access article distributed under the terms of the Creative Commons Attribution Non-Commercial License (http://creativecommons.org/ licenses/by-nc/4.0) which permits unrestricted noncommercial use, distribution, and reproduction in any medium, provided the original work is properly cited. Copyright $\odot 2018$ by Korean Academy of Rehabilitation Medicine 


\section{INTRODUCTION}

Though there have been advances in medicine, industry, and technology, amputation remains a leading cause of disability [1]. The incidence of amputations is not expected to subside because of the aging population and the increased incidence of diabetes. As the population ages, the number of amputations in persons older than 65 years is expected to double [2]. Also, amputation secondary to vascular conditions and is rapidly increasing in incidences $[3,4]$. In one study, amputation prevalence was predicted to be more than doubled from 2005 to 2050 [5]. In Korea, transtibial amputation constitutes the largest percentage of limb amputations [6].

Additional attention on this topic is needed as the incidence of transtibial amputation is increasing in number. Proper prosthesis is integral for rehabilitation and functional recovery in lower limb amputation. Prosthetic foot component choice is a crucial factor that affects gait pattern in transtibial amputees. Well-designed gait analysis can provide objective information about prosthetic components and an accurate understanding of each prosthetic foot will help to prescribe an optimal prosthetic foot for a patient.

Currently, various types of prosthetic feet are in use according to the individual circumstances of the patient [7]. Articulated feet have a mobile joint that connect foot and shank. Various single-axis and multi-axis feet are made into prosthetic feet. A passive foot has a single structure of foot and ankle. Solid ankle cushion heel and stationary ankle flexible endoskeletal are included in this study. Passive prosthetic feet provide material with minimal energy storage and return over the stance phase due to their high stiffness and limited deflection. Therefore, they provide few biomechanical advantages $[8,9]$.

In an effort to improve performance, carbon fiber energy storing feet were developed. This prosthetic foot stores elastic energy during the stance when it provides body support and releases it at end of the stance phase. Then it provides forward propulsion and helps initiate leg swing [10]. An energy storing foot can reduce the user's energy consumption and also has advantages on uneven terrain. It can also adjust with various gait speeds since it is composed of flexible material [11]. Because of these advantages, energy storing feet are increasing in use replacing non-energy storing passive foot prosthetics [12]. Energy storing feet of various shapes and levels of stiffness are on the market, but the differences between those subtypes have not been clearly evaluated yet. Currently, clinicians tend to base prosthetic prescription on clinical experience rather than objective data. Thus, studies are needed to assess the influence of prosthetic foot on gait. One study identified the influence of foot stiffness or extension of flexible material on energy storing feet. However, there are few studies that evaluate the influence of the shape of an energy storing foot $[13,14]$.

Therefore, we conducted a study to evaluate if there is any difference in gait pattern when applying two different shapes of energy storing foot.

\section{MATERIALS AND METHODS}

Ten unilateral transtibial amputees were recruited. All subjects were asymptomatic of musculoskeletal disorders and pain and were proficient walkers who did not use assistive devices. Subjects provided informed consent to an Institutional Review Board approved protocol prior to participation. General characteristics such as gender, age, amputee side, height, period since amputation and functional state were collected. Functional state was expressed as $\mathrm{K}$ level, which is a rating system adopted by Medicare to indicate a lower limb amputee's rehabilitation potential. This system rates from 0 to 4 the higher the rating the increasing functional mobility and the patient functional level as it is widely defined $[1,15]$ (Table 1).

Two different types of dynamic response feet 1C30 Trias (Ottobock, Duderstadt, Germany) and 1C60 Triton (Ottobock) were applied to each subject. Both prosthetic feet are made with interconnected dual spring elements that provide energy return and are suited for patients that are capable for everyday life. The biggest difference between the two prosthetic feet is the forefoot shape and heel wedge. A forefoot spring is split and a wedge is inserted in the heel spring of 1C60 Triton (Fig. 1).

Prior to use, a certified and licensed prosthetist ensured proper fit and alignment. No subjects had experience with energy storing feet prosthetics prior to this study. Subjects used two prosthetic feet connected to their own prosthesis for a week each in random order. At the end of the week gait analysis was performed. Subjects were instructed to walk at a self-selected pace along a 10-meter walkway consisting of three embedded force plates. 
Table 1. K-level functional classification system

\begin{tabular}{cc}
\hline Level & Description \\
\hline K0 & $\begin{array}{c}\text { Does not have the ability or potential to ambulate or transfer safely with or without assistance, and a pros- } \\
\text { thesis does not enhance quality of life or mobility. }\end{array}$ \\
K1 & $\begin{array}{c}\text { Has the ability or potential to use a prosthesis for transfers or ambulation on level surfaces at fixed cadence } \\
\text { typical of the limited and unlimited household ambulator. }\end{array}$ \\
K2 & $\begin{array}{c}\text { Has the ability or potential for ambulation with low-level environmental barriers such as curbs, stairs, and } \\
\text { uneven surfaces. Typical of the limited community ambulator. }\end{array}$ \\
K3 & $\begin{array}{c}\text { Has the ability or potential for ambulation with variable cadence. } \\
\text { Typical of the community ambulator who can traverse most environmental barriers and has vocational, } \\
\text { therapeutic, or exercise activity that demands prosthetic utilization beyond simple locomotion. }\end{array}$ \\
K4 $\begin{array}{c}\text { Has the ability or potential for prosthetic ambulation that exceeds basic ambulation skills, exhibiting high } \\
\text { impact, stress, or energy levels Typical of the prosthetic demands of the child, active adult, or athlete. }\end{array}$ \\
\hline
\end{tabular}
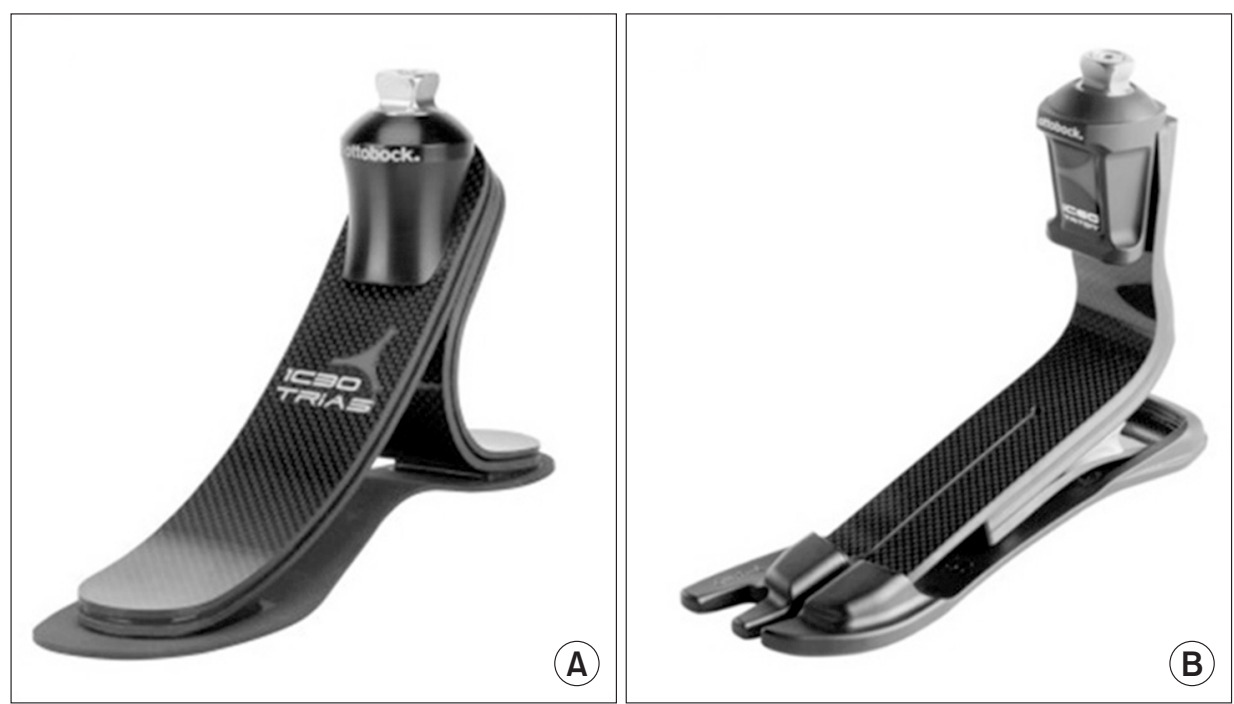

Fig. 1. Exterior of the two types of prosthetic feet: (A) 1C30 Trias and (B) 1 C60 Triton.
Spatiotemporal (cadence, speed, step width, step length, stance, and swing phase ratio), kinematic (ankle plantarflexion angle at initial contact, ankle dorsiflexion angle through mid-stance, ankle plantarflexion angle at end of stance, ankle pronation during early mid-stance and ankle supination at onset of preswing, knee flexion angle at terminal stance, knee flexion angle at mid swing, hip extension angle at terminal stance, and hip flexion angle at mid swing) and kinetic (ankle plantarflexion moment at end of stance) data of both lower limbs was obtained through gait analysis (Motion Analysis Corp., Santa Rosa, CA, USA).

Differences of gait pattern between the two prosthetics and between the intact side and prosthetic side were accessed to identify any gait asymmetry.

All statistical analyses were performed using SPSS ver- sion 18.0 (SPSS Inc., Chicago, IL, USA). A Wilcoxonsigned rank test was used to assess the differences of gait analysis results between intact and prosthetic limbs and between the two prosthetic feet. A p-value $<0.05$ was considered statistically significant.

\section{RESULTS}

\section{Characteristics}

Ten subjects were all male, 7 subjects were amputated on the right side and 3 were amputated on the left side. Four subjects had activity level of K2 and 6 subjects had

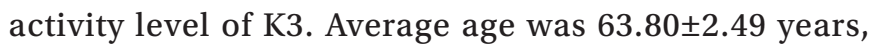
average height was $170.29 \pm 5.56 \mathrm{~cm}$, and average period since amputation was $36.57 \pm 9.71$ months. 


\section{Spatiotemporal}

On a side to side comparison, slight cadence asymmetry with 1C30 Trias was observed. Otherwise no asymmetry was noted with both prosthetic feet in step width, step length, stance, and swing ratio.

On a comparison between prosthetics, the ratio of stance and swing phase was closer to normal with 1C60 Triton than with 1C30 Trias (Table 2).

\section{Kinematic}

On a side to side comparison, ankle plantarflexion angle at the end of stance and ankle supination at the onset of the preswing was decreased in the prosthetic side irrespective of prosthesis type. There was no asymmetry between intact and prosthesis side in ankle plantarflexion angle at initial contact, no ankle dorsiflexion angle through midstance, and no ankle pronation during early midstance. Knee and hip angle showed no differences between intact and prosthesis side.

On a comparison between prosthetics, ankle dorsiflexion angle through midstance was far closer to normal with 1C60 Triton than 1C30 Trias. The 1C30 Trias showed a dorsiflexion angle that exceeded normal range. There was no significant difference between two prosthetics in other parameters including the knees and hips (Tables 3, 4).

\section{Kinetics}

Available kinetic parameters were obtained from only five subjects because of a recording error on the prosthetic side. There was no significant difference in ankle plantarflexion movement during the terminal stance phase on a side to side comparison and a between prosthetics

Table 2. Spatiotemporal parameters $(n=10)$

\begin{tabular}{|c|c|c|c|c|c|c|c|}
\hline & \multicolumn{3}{|c|}{1 C30 Trias $(n=10)$} & \multicolumn{3}{|c|}{1 C60 Triton $(n=10)$} & \multirow{2}{*}{-p-value ${ }^{a)}$} \\
\hline & Intact & Prosthetic & p-value & Intact & Prosthetic & p-value & \\
\hline Cadence (steps/min) & $105.9 \pm 9.2$ & $103.9 \pm 9.6$ & $0.009^{*}$ & $105.8 \pm 8.6$ & $104.9 \pm 8.8$ & 0.273 & 0.724 \\
\hline Speed $(\mathrm{cm} / \mathrm{s})$ & $110.23 \pm 13.30$ & $111.11 \pm 13.13$ & 0.834 & $113.52 \pm 15.68$ & $113.56 \pm 13.47$ & 0.650 & 0.830 \\
\hline Step width (cm) & $16.0 \pm 3.1$ & $16.0 \pm 3.1$ & - & $15.8 \pm 3.1$ & $15.8 \pm 3.1$ & - & 0.813 \\
\hline Step length $(\mathrm{cm})$ & $62.2 \pm 9.3$ & $65.9 \pm 9.4$ & 0.479 & $65.5 \pm 11.9$ & $67.3 \pm 7.2$ & 0.687 & 0.581 \\
\hline Stance (\% cycle) & $64.0 \pm 5.0$ & $64.3 \pm 3.2$ & 0.884 & $62.4 \pm 6.3$ & $61.8 \pm 2.9$ & 0.829 & $0.005^{*}$ \\
\hline Swing (\% cycle) & $35.9 \pm 5.0$ & $35.7 \pm 3.3$ & 0.903 & $37.5 \pm 6.3$ & $38.2 \pm 2.7$ & 0.829 & $0.006^{*}$ \\
\hline
\end{tabular}

Values are presented as mean \pm standard deviation.

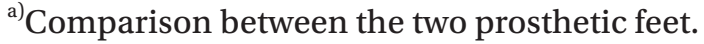

${ }^{*} \mathrm{p}<0.05$.

Table 3. Kinematic parameters of ankle joint $(n=10)$

\begin{tabular}{|c|c|c|c|c|c|c|c|}
\hline & \multicolumn{3}{|c|}{$1 C 30$ Trias $(n=10)$} & \multicolumn{3}{|c|}{1 C60 Triton $(n=10)$} & \multirow{2}{*}{-p-value ${ }^{a}$} \\
\hline & Intact & Prosthetic & p-value & Intact & Prosthetic & p-value & \\
\hline $\begin{array}{l}\text { Ankle plantarflexion angle at } \\
\text { initial contact }\left(^{\circ}\right)\end{array}$ & $-4.93 \pm 4.54$ & $-5.83 \pm 5.28$ & 0.561 & $-5.08 \pm 2.54$ & $-5.89 \pm 3.45$ & 0.633 & 0.970 \\
\hline $\begin{array}{l}\text { Ankle dorsiflexion angle through } \\
\text { midstance }\left(^{\circ}\right)\end{array}$ & $17.12 \pm 3.81$ & $19.46 \pm 3.58$ & 0.094 & $14.98 \pm 4.15$ & $15.28 \pm 3.23$ & 0.828 & $0.000^{*}$ \\
\hline $\begin{array}{l}\text { Ankle plantarflexion angle at } \\
\text { end of stance }\left(^{\circ}\right)\end{array}$ & $-12.41 \pm 5.52$ & $0.40 \pm 5.97$ & $0.000^{*}$ & $-13.13 \pm 6.24$ & $0.61 \pm 5.84$ & $0.002^{*}$ & 0.858 \\
\hline $\begin{array}{l}\text { Ankle pronation during early } \\
\text { midstance }\end{array}$ & $2.02 \pm 1.30$ & $2.30 \pm 1.57$ & 0.661 & $2.09 \pm 1.18$ & $2.17 \pm 1.32$ & 0.914 & 0.575 \\
\hline $\begin{array}{l}\text { Ankle supination at onset of } \\
\text { preswing }\end{array}$ & $-2.94 \pm 1.92$ & $-0.91 \pm 0.83$ & $0.016^{*}$ & $-3.63 \pm 2.78$ & $-0.77 \pm 1.03$ & $0.016^{*}$ & 0.386 \\
\hline
\end{tabular}

Values are presented as mean \pm standard deviation.

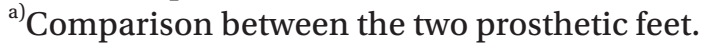

${ }^{*} \mathrm{p}<0.05$. 
Table 4. Kinematic parameters of hip and knee joint $(n=10)$

\begin{tabular}{|c|c|c|c|c|c|c|c|}
\hline & \multicolumn{3}{|c|}{$1 C 30$ Trias $(n=10)$} & \multicolumn{3}{|c|}{1 C60 Triton $(n=10)$} & \multirow{2}{*}{ p-value } \\
\hline & Intact & Prosthetic & p-value & Intact & Prosthetic & p-value & \\
\hline Hip extension angle at terminal stance & $-7.18 \pm 8.13$ & $-6.99 \pm 8.37$ & 0.941 & $-6.56 \pm 8.00$ & $-6.40 \pm 8.90$ & 0.886 & 0.898 \\
\hline Hip flexion angle at mid swing & $34.85 \pm 4.98$ & $35.67 \pm 4.95$ & 0.533 & $33.98 \pm 4.76$ & $35.61 \pm 6.38$ & 0.744 & 0.825 \\
\hline Knee flexion angle at terminal stance & $3.06 \pm 4.75$ & $2.97 \pm 4.01$ & 0.527 & $4.29 \pm 4.45$ & $3.17 \pm 3.52$ & 0.523 & 0.838 \\
\hline Knee flexion angle at mid swing & $62.72 \pm 2.67$ & $59.62 \pm 5.05$ & 0.098 & $61.62 \pm 5.96$ & $61.31 \pm 5.02$ & 0.999 & 0.889 \\
\hline
\end{tabular}

Values are degree angles and presented as mean \pm standard deviation.

${ }^{\text {a) }}$ comparison between the two prosthetic feet.

Table 5. Kinetic parameters $(\mathrm{n}=5)$

\begin{tabular}{|c|c|c|c|c|c|c|c|}
\hline & \multicolumn{3}{|c|}{1 C30 Trias $(n=5)$} & \multicolumn{3}{|c|}{1 C60 Triton $(n=5)$} & \multirow{2}{*}{ p-value ${ }^{\text {a) }}$} \\
\hline & Intact & Prosthetic & p-value & Intact & Prosthetic & p-value & \\
\hline $\begin{array}{l}\text { Ankle plantarflexion moment at end } \\
\text { of stance }(\mathrm{Nm} / \mathrm{kg})\end{array}$ & $1.63 \pm 0.64$ & $1.04 \pm 0.54$ & 0.248 & $1.76 \pm 0.51$ & $1.11 \pm 0.24$ & 0.100 & 0.812 \\
\hline
\end{tabular}

Values are presented as mean \pm standard deviation.

${ }^{\text {a) }}$ Comparison between the two prosthetic feet.

comparison (Table 5).

\section{DISCCUSION}

Unilateral transtibial amputations often lead to reduced walking speed, gait asymmetries, and altered residual leg muscle activity relative to non-amputee walkers $[16,17]$. Absence of the ankle plantarflexor muscles, which provide needed body support, forward propulsion, and swing initiation during non-amputee walking, is the main contributing factor [18]. To support the absence of the ankle plantarflexor muscles, dynamic response feet that are made of carbon fiber were developed. Energy storing feet store energy during the stance phase of ankle dorsiflexion and release it during toe off, provide body support, forward propulsion, and leg swing initiation $[10,19]$. This reduces the user's oxygen and energy consumption while walking [20]. Accordingly, various types of energy storing feet have been developed and prescribed in clinical practice. An energy storing prosthetic foot is composed of a number of elements such as materials with various elasticities, an extension of elastic material, and in the shape of a foot. Two prosthetic feet used in this study are representative of the types of shapes available. The 1C30 Trias represents a unitary foot and the 1C60 Triton represents a split foot. Energy storing feet may be expected to have an affect the shape of gait, but this has not been established yet in prior studies. Basic information about the differences between the two shapes is necessary to prescribe an optimal energy storing foot.

In this study, two commonly prescribed shapes of energy storing feet made of a lightweight, flexible carbon fiber from a single manufacturer are used.

The 1C30 Trias is made with three springs: heel, forefoot, and base spring. The C-shaped heel spring guarantees shock absorption at heel strike. A single structure forefoot spring is flexible to ensure smooth roll over and energy storing during stance phase and returns it at the end of the stance phase releasing power. Its base spring joins the forefoot spring and heel spring.

The 1C60 Triton is also made with three springs: the heel, forefoot, and base springs. The split forefoot with base spring is a noticeable characteristic of 1C60 Triton. The split separates the big toe and helps to adapt to various surfaces. The heel spring is also different with that of 1C30 Trias. Two separate carbon fiber plates connected with a wedge form the heel spring of 1C60 Triton, while a single carbon fiber plate curved in a C-shape forms the heel spring of 1C30 Trias. This wedge plays a role as a shock absorber and makes 1C60 Triton more suitable for high performance tasks such as running.

\section{Spatiotemporal}

In this study, slight cadence asymmetry was observed 
with 1C30 Trias in a side to side comparison. The rest of the parameters measured imply a symmetric gait with both energy storing feet models. This result is consistent with previous studies that showed energy storing feet are superior to passive prosthetic feet in the characteristics of faster walking speed, longer stance phase, and more equal length of step length $[21,22]$.

Between prosthetic models, stance and swing ratio was closer to normal with 1C60 Triton than with 1C30 Trias meaning there was a more symmetric gait with 1C60 Triton. Prolonged stance ratio with 1C30 Trias might be the result of slower gait speed, though there was not a statically significant difference.

\section{Kinematic}

In normal conditions, initial contact by heel occurs with ankle plantar flexed at about $3^{\circ}$ to $5^{\circ}$. With the onset of the forefoot contact the ankle changes its direction to dorsiflexion. Dorsiflexion continues through midstance reaching a maximum at $10^{\circ}$. At the end of the stance, rapid ankle plantarflexion occurs reaching a maximum $20^{\circ}$ pushing against the floor [23].

In this study, asymmetry between intact and prosthetic side was noted in ankle plantarflexion at the end of stance. Active plantarflexion exceeded a neutral position and did not occur with prosthesis though it stored energy during dorsiflexion. We will discuss the moment generated at this time in the kinetic section below.

Supination angle at the onset of the preswing was smaller with both prosthetics compared with the intact sides. We expected that the split spring of 1C60 Triton would make movement in coronal dimension, but supination angle was smaller with both prosthetics compared with the intact sides. This result may be explained by the absence of a plantar arch in the prosthetic feet. And the split spring of 1C60 Triton maybe did not have a chance to move functionally since the gait analysis was done on an even and barrier-free floor.

Excessive dorsiflexion is an important characteristic of an energy storing foot that reflects energy stored while supporting weight. In a previous study, an energy storing foot showed greater peak ankle dorsiflexion at push-off compared with a multi-axis foot on a gait analysis performed on 6 unilateral transfemoral amputees; $18.5^{\circ} \pm 4.7^{\circ}$ with an energy storing foot, $12.9^{\circ} \pm 3.4^{\circ}$ with a multi-axis foot $(p=0.001)$ [21]. This was also observed in our study though the differences were not statistically significant compared to the intact side. Other parameters showed no significant differences between intact and prosthetic side and therefore, suggested symmetry.

Between prosthetics, dorsiflexion angle of 1C30 Trias was significantly larger than that of 1C60 Triton. The inserted heel wedge might have less affects on excessive ankle dorsiflexion of 1C60 Triton. Those structural characteristics must make the 1C60 Triton stiffer, but more effective to absorb shock.

Besides that of the ankle, kinematic data of knees and hip joints were also evaluated. We analyzed kinetics at the terminal stance where maximal ankle plantar flexion occurs and at the mid swing where maximum knee and hip flexion occurs. Under normal conditions, the knee gradually extends during mid stance and reaches minimum flexion state at the end of a terminal stance on average $3^{\circ}$. The hip moves to extension until about $-10^{\circ}$ during stance. At mid-swing the knee reaches maximal flexion at about $60^{\circ}$, the hip reaches a maximal flexion at $40^{\circ}$. Consistent results were derived in our study, regardless of the type of prosthetic foot. These results mean that both types of prosthetic feet used in this study enable normalized knee and hip movements.

\section{Kinetic}

At the terminal stance, the ankle plantarflexion moment is generated by 1.5 times of the body weight under normal conditions. No articulated foot or passive foot can generate power exceeding a user's body weight. A relatively strong plantarflexion moment is generated by an energy storing foot compared with the passive prosthetic foot. This corresponds to increased dorsiflexion moment in the loading response $[9,24]$. The effect of prosthetic foot type on knee moment is controversial. No articulated or passive foot typically produces a dominant flexor moment during loading response [25]. Some investigations showed reversal of flexor moment to an extensor moment as a loading response with energy storing feet $[25,26]$. But in other studies, the energy storing foot maintained an extensor moment throughout stance $[27,28]$. The increased hip extensor moment in loading response reported in a previous study was not statistically significant [26].

In this study, the plantarflexion moment seems to be smaller with both prosthetic feet compared to the intact 
side though it was not statistically significant. This result implies that the energy storing foot can generate a force close to a normal force at terminal stance. This is consistent with previous studies that describe the influence of the stiffness of the prosthetic material [13].

Lack of kinetic data is a major limitation of this study. Kinetic change over gait phases and relations between joints need to be fully evaluated in future studies. We compared spatiotemporal and kinematic results of five subjects with kinetic data and five subjects without kinetic data, since there is possibility that certain features of the gaits might affect the kinetic characteristics. We concluded that it may just be a technical error because there was no difference between the two groups. This is still a limitation of this study. Other limitations include the small number of patients, inclusion of patients with certain functional level and restricted assessment environments. In future studies, larger number of patients with diverse functional levels should be included and an analysis with a low error rate should be done.

\section{Conclusion}

Energy storing feet implement symmetric gait in unilateral transtibial amputees who are functionally independent in daily living. The 1C60 Triton showed a gait pattern closer to normal than the 1C30 Trias in the aspect of stance-swing ratio and ankle dorsiflexion angle. The more complex shape might mean higher initial costs as well as higher maintenance costs. Based on the increased understanding of each prosthetic, it is necessary to prescribe a proper prosthetic considering individual characteristics such as functional level, living environment, and socio-economic status.

\section{CONFLICT OF INTEREST}

No potential conflict of interest relevant to this article was reported.

\section{REFERENCES}

1. Braddom RL, Chan L, Harrast MA, Kowalske KJ, Matthews DJ, Ragnarsson KT, et al. Physical medicine and rehabilitation. 4th ed. Philadelphia: Elsevier Health Sciences; 2010.

2. Fletcher DD, Andrews KL, Hallett JW Jr, Butters MA,
Rowland CM, Jacobsen SJ. Trends in rehabilitation after amputation for geriatric patients with vascular disease: implications for future health resource allocation. Arch Phys Med Rehabil 2002;83:1389-93.

3. Dillingham TR, Pezzin LE, MacKenzie EJ. Limb amputation and limb deficiency: epidemiology and recent trends in the United States. South Med J 2002;95:87583.

4. Varma P, Stineman MG, Dillingham TR. Epidemiology of limb loss. Phys Med Rehabil Clin N Am 2014;25:1-8.

5. Ziegler-Graham K, MacKenzie EJ, Ephraim PL, Travison TG, Brookmeyer R. Estimating the prevalence of limb loss in the United States: 2005 to 2050. Arch Phys Med Rehabil 2008;89:422-9.

6. Kim SH, Beon YC, Son CK, Lee YH, Lee MK, Lee SH, et al. A survey study on prevalence and condition of the disabled in the Korea. Sejong: Ministry of Health and Welfare; 2011.

7. Paradisi F, Delussu AS, Brunelli S, Iosa M, Pellegrini $\mathrm{R}$, Zenardi D, et al. The conventional non-articulated $\mathrm{SACH}$ or a multiaxial prosthetic foot for hypomobile transtibial amputees? A clinical comparison on mobility, balance, and quality of life. ScientificWorldJournal 2015;2015:261801.

8. Ehara Y, Beppu M, Nomura S, Kunimi Y, Takahashi S. Energy storing property of so-called energy-storing prosthetic feet. Arch Phys Med Rehabil 1993;74:68-72.

9. Hafner BJ, Sanders JE, Czerniecki J, Fergason J. Energy storage and return prostheses: does patient perception correlate with biomechanical analysis? Clin Biomech (Bristol, Avon) 2002;17:325-44.

10.Zmitrewicz RJ, Neptune RR, Sasaki K. Mechanical energetic contributions from individual muscles and elastic prosthetic feet during symmetric unilateral transtibial amputee walking: a theoretical study. J Biomech 2007;40:1824-31.

11. Agrawal V, Gailey R, O'Toole C, Gaunaurd I, Finnieston A. Influence of gait training and prosthetic foot category on external work symmetry during unilateral transtibial amputee gait. Prosthet Orthot Int 2013;37:396-403.

12. Wezenberg D, Cutti AG, Bruno A, Houdijk H. Differentiation between solid-ankle cushioned heel and energy storage and return prosthetic foot based on step-tostep transition cost. J Rehabil Res Dev 2014;51:157990. 
13. Fey NP, Klute GK, Neptune RR. The influence of energy storage and return foot stiffness on walking mechanics and muscle activity in below-knee amputees. Clin Biomech (Bristol, Avon) 2011;26:1025-32.

14. Rigney SM, Simmons A, Kark L. Mechanical characterization and comparison of energy storage and return prostheses. Med Eng Phys 2017;41:90-6.

15. Gailey RS, Roach KE, Applegate EB, Cho B, Cunniffe $\mathrm{B}$, Licht $\mathrm{S}$, et al. The amputee mobility predictor: an instrument to assess determinants of the lower-limb amputee's ability to ambulate. Arch Phys Med Rehabil 2002;83:613-27.

16. Fey NP, Silverman AK, Neptune RR. The influence of increasing steady-state walking speed on muscle activity in below-knee amputees. J Electromyogr Kinesiol 2010;20:155-61.

17. Silverman AK, Fey NP, Portillo A, Walden JG, Bosker G, Neptune RR. Compensatory mechanisms in belowknee amputee gait in response to increasing steadystate walking speeds. Gait Posture 2008;28:602-9.

18. Neptune RR, Kautz SA, Zajac FE. Contributions of the individual ankle plantar flexors to support, forward progression and swing initiation during walking. J Biomech 2001;34:1387-98.

19. Hafner BJ, Sanders JE, Czerniecki JM, Fergason J. Transtibial energy-storage-and-return prosthetic devices: a review of energy concepts and a proposed nomenclature. J Rehabil Res Dev 2002;39:1-11.

20. Graham LE, Datta D, Heller B, Howitt J. A comparative study of oxygen consumption for conventional and energy-storing prosthetic feet in transfemoral ampu- tees. Clin Rehabil 2008;22:896-901.

21. Graham LE, Datta D, Heller B, Howitt J, Pros D. A comparative study of conventional and energy-storing prosthetic feet in high-functioning transfemoral amputees. Arch Phys Med Rehabil 2007;88:801-6.

22. Svoboda Z, Janura M, Cabell L, Elfmark M. Variability of kinetic variables during gait in unilateral transtibial amputees. Prosthet Orthot Int 2012;36:225-30.

23. Perry J, Burnfield JM. Gait analysis: normal and pathological function. 2nd ed. Thorofare: Slack Inc.; 2010.

24. Castro MP, Soares D, Mendes E, Machado L. Plantar pressures and ground reaction forces during walking of individuals with unilateral transfemoral amputation. PM R 2014;6:698-707.

25. Gitter A, Czerniecki JM, DeGroot DM. Biomechanical analysis of the influence of prosthetic feet on below-knee amputee walking. Am J Phys Med Rehabil 1991;70:142-8.

26. Schneider K, Hart T, Zernicke RF, Setoguchi Y, Oppenheim W. Dynamics of below-knee child amputee gait: SACH foot versus Flex foot. J Biomech 1993;26:1191204.

27. Torburn L, Perry J, Ayyappa E, Shanfield SL. Belowknee amputee gait with dynamic elastic response prosthetic feet: a pilot study. J Rehabil Res Dev 1990;27:369-84.

28. Colborne GR, Naumann S, Longmuir PE, Berbrayer D. Analysis of mechanical and metabolic factors in the gait of congenital below knee amputees: a comparison of the SACH and Seattle feet. Am J Phys Med Rehabil 1992;71:272-8. 